\title{
PAPER
}

\section{Chronic alcohol use and first symptomatic epileptic seizures}

\section{Leone, C Tonini, G Bogliun, F Monaco, R Mutani, E Bottacchi, P Gambaro, E Rocci, T Tassinari, C Cavestro, E Beghi, for the ARES (Alcohol Related Seizures) Study Group}

See end of article for authors' affiliations

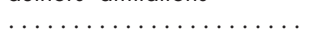

Correspondence to: $\operatorname{Dr} M$ Leone, Clinica Neurologica, Ospedale Maggiore, C. Mazzini 18, 28100 Novara, Italy; leomau@iol.it

Received 11 April 2002 In revised form 12 July 2002

Accepted 8 August 2002
J Neurol Neurosurg Psychiatry 2002;73:495-499

Objective: To establish whether chronic alcoholism and alcohol consumption are risk factors for developing a first symptomatic epileptic seizure.

Methods: Multicentre case-control study of 293 patients (160 men, 133 women) with a first seizure symptomatic (either acute or remote) of head trauma, stroke, or brain tumour, matched to 444 hospital controls for centre, sex, age ( \pm 5 years), and underlying pathology.

Results: The risk of first seizure in alcoholics was no higher than in non-alcoholics for men (odds ratio $1.2,95 \%$ confidence interval 0.4 to 3.2 ) or women $(1.5,0.1$ to 54.4$)$. The odds ratio (both sexes) was $1.2(0.8$ to 1.7$)$ for an average intake of absolute alcohol of $1-25 \mathrm{~g} /$ day, $0.9(0.5$ to 1.5$)$ for $26-50$ $\mathrm{g} /$ day, 1.6 (0.8 to 3.0) for 51-100 g/day, and $1.4(0.5$ to 3.5$)$ for $>100 \mathrm{~g} /$ day.

Conclusions: We found no evidence of an association between alcohol use or alcoholism and a first symptomatic seizure.
S ymptomatic epileptic seizures, according to the guidelines for epidemiological studies on epilepsy, ${ }^{1}$ are classified as provoked or unprovoked, depending on the time between the insult to the central nervous system (CNS) and the seizure. Provoked is equivalent to acute symptomatic, and unprovoked symptomatic includes seizures with a presumed remote cause, or owing to progressive CNS disorders. Three aetiological factors (stroke, head trauma, and brain tumours) account for half to two thirds of symptomatic seizures in incidence studies in adults. ${ }^{23}$ Alcohol use was one of the strongest risk factors for a first seizure, ${ }^{45}$ with a dose-relation for idiopathic/cryptogenic seizures; the risk was also evident for symptomatic seizures, although lower and with a less clear trend. In both these studies, however, the sample for symptomatic seizures was small.

We therefore designed a study to establish whether alcohol consumption is a risk factor for a first symptomatic seizure. Since alcohol use might also have a confounding effect for some "aetiologies", ${ }^{67}$ we considered confounding in our study design. Secondary objectives were to estimate these risks in different patient subgroups based on sex and type of seizure (acute or remote symptomatic), and in relation to the underlying "cause" (stroke, head trauma, and brain tumour).

\section{PATIENTS AND METHODS}

This was a multicentre case-control study in Northern Italy. Eighteen referral neurological and neurosurgical departments in Northern Italy participated.

\section{Cases and controls \\ Cases}

We studied patients consecutively admitted to one of the participating hospitals with either a first ever seizure, or a first medically evaluated seizure. Seizures were classified according to the 1981 proposal for Revised Clinical and Electroencephalographic Classification of Epileptic Seizures. ${ }^{8}$ A first seizure was defined as the first seizure (or the first cluster of seizures within a 24 hour period) ever experienced by the patient, excluding febrile seizures; a first medically evaluated seizure was the first seizure ever evaluated by a physician in patients who had had previously unevaluated seizures of any type. Seizures were divided into provoked (occurred in close temporal association with an acute brain insult), unprovoked symptomatic (secondary to conditions resulting in static encephalopathy, or associated with a progressive CNS disorder), and unprovoked of unknown aetiology (including idiopathic and cryptogenic), on the basis of history, clinical examination, electroencephalography (EEG), and computed tomography (CT) results. In this paper we will use the terms acute symptomatic and remote symptomatic as the equivalent of provoked and unprovoked symptomatic, and idiopathic/cryptogenic as the equivalent of unprovoked unknown cause.

No assumptions were made with regard to the effects of alcohol: seizures occurring during alcohol withdrawal and in persons with a history of chronic alcohol abuse were therefore divided into idiopathic/cryptogenic, acute, or remote symptomatic solely on the absence or presence of an insult to the CNS, its type, and its time relation with the seizure. Patients with only CT signs of previous asymptomatic hemispheric stroke were classified as remote symptomatic seizures. A panel of three neurologists (ML, CT, GB) decided on the inclusion or exclusion of cases which could not be easily classified. When a patient presented concurrent remote and acute insults to the CNS, the seizure was classified as acute symptomatic.

Inclusion criteria were: age 15 years or older; having had a seizure in the 48 hours before hospital admission; evaluation by a neurologist; seizure described by eye witnesses (93\% of cases); or, for generalised tonic-clonic seizures, at least three of the following criteria: loss of consciousness, urinary or faecal incontinence, laceration of tongue or cheek, and post-ictal confusion or Todd's paralysis. ${ }^{4}$

Between January 1995 and October 1998 we observed 725 first seizures or first medically evaluated seizures, 340 idiopathic/cryptogenic seizures, and 385 symptomatic seizures. Only seizures symptomatic of stroke, head trauma, or brain tumour were included in the study $(\mathrm{n}=324)$. Five cases

Abbreviations: ADAA, average daily intake of absolute alcohol; CNS, central nervous system; CT, computed tomography; EEG, electroencephalography; $\gamma-\mathrm{GT}$, gamma-glutamyl-transpeptidase; MALT, Münchner Alkoholismustest; MCV, mean corpuscular volume; OR, odds ratio 
were excluded because they presented a dual aetiology (for example, stroke and brain tumour). The other aetiologies of symptomatic seizures were: cerebral atrophy $(n=22)$, multiinfarct dementia $(\mathrm{n}=8)$, CNS infection $(\mathrm{n}=8)$, blood electrolyte disorder $(\mathrm{n}=3)$, perinatal encephalopathy $(\mathrm{n}=4)$, multiple sclerosis $(\mathrm{n}=2)$, and other CNS disorder $(\mathrm{n}=9)$.

\section{Controls}

We found two controls for each case from the list of patients admitted to the emergency room, with a negative history of epileptic seizures (excluding febrile seizures). We excluded five possible controls who did not drink alcohol for religious reasons or lifestyle rules (no case was forbidden to drink for these reasons). The first two controls that matched the case were interviewed. Controls were matched to cases according to centre, age ( \pm 5 years), sex, and timing and type of the CNS insult. For example, we matched acute symptomatic seizures after stroke and head trauma (that is, occurring within seven days) to controls with stroke or head trauma in the seven days preceding the interview. Remote symptomatic seizures from stroke and head trauma were matched to controls with the same conditions occurring more than seven days before interview. Seizures occurring as the presenting symptom of a brain tumour (acute symptomatic) were matched to controls with a brain tumour diagnosed within one week; other seizures in patients with a brain tumour (remote symptomatic) were matched to controls with a brain tumour diagnosed more than a week before the interview. Controls of patients with remote symptomatic seizures had to have an interval between CNS insult and study entry at least equal to that of the matched case.

\section{Definition of the cause}

Stroke was defined according to the WHO criteria, ${ }^{9}$ as the acute onset of neurological symptoms of presumed vascular origin and $>24$ hours duration. Head trauma and brain tumours were accepted when diagnosed by the attending neurologist. Brain tumours included primary and secondary tumours, and arteriovenous malformations.

\section{Design of the questionnaire and data quality}

The questionnaire collected information on demographic data (sex, level of education, marital status, residence, place of birth, occupation); family history of seizures; prenatal, perinatal, and postnatal risk factors; and problems related to alcoholism (family history of alcoholism and use of illicit drugs; number of road accidents, jail convictions, dismissals from work, and hospital admissions for alcohol abuse). Specific information on the preparation and validation of the questionnaire and the definitions of the risk factors are reported elsewhere. ${ }^{510}$

Subjects were classified according to their current drinking status as: non-drinkers if they drank less than once a year"; ex-drinkers if they had abstained from drinking for at least one year and had previously drunk at least once a month ${ }^{4}$; occasional drinkers if they drank at least once a year, but less than once a month; or current drinkers if they did not fit into any of the previous categories. Current drinkers were classified according to their drinking habits during the week (continuous versus binge drinkers) and during the day (at-meal versus between-meals drinkers). Continuous drinkers were persons who drank every day of the week, binge drinkers those who drank only, or considerably more, at the weekend in terms of both quantity and frequency. At-meal drinkers were those who drank only during meals, between-meals drinkers those who drank at meals and between meals. Subjects were asked about the age at starting and, for ex-drinkers, at stopping drinking, and their patterns of drinking.

The average daily intake of absolute alcohol (ADAA) in the six months before inclusion in the study, or before stopping
Table 1 Cases and controls according to time and type of symptomatic seizure

\begin{tabular}{llll}
\hline & No. & $\%$ & Ratio \\
\hline Acute symptomatic controls/cases & & \\
Stroke & $193 / 105$ & $44 / 36$ & 1.8 \\
Head trauma & $13 / 10$ & $3 / 3$ & 1.3 \\
Brain tumour & $121 / 102$ & $27 / 35$ & 1.2 \\
Total & $327 / 217$ & $74 / 74$ & 1.5 \\
& & & \\
Remote symptomatic controls/cases & & \\
Stroke & $86 / 56$ & $19 / 19$ & 1.5 \\
Head trauma & $18 / 13$ & $4 / 4$ & 1.4 \\
Brain tumour & $13 / 7$ & $3 / 2$ & 1.9 \\
Total & $117 / 76$ & $26 / 26$ & 1.5 \\
\hline & &
\end{tabular}

drinking for ex-drinkers, was calculated for each person, asking separately about white and red wine, beer, aperitifs, "bitters", spirits, and laced coffee to obtain the number of servings drunk per occasion, the number of occasions per day, and the number of days per week. We multiplied the number of servings per drinking occasion by the number of occasions per day by the number of days per week to calculate the number of servings per week for each beverage. This number was multiplied by the average alcohol content (grams) of each beverage, and the total of all beverages was divided by seven to calculate the ADAA in grams per day. ${ }^{10}$

The diagnosis of chronic alcoholism was based on the Münchner Alkoholismustest (MALT). ${ }^{11}$ A MALT score under 6 is normal, between 6 and 10 is borderline, and above 10 is diagnostic for alcoholism. Instructions were given on how to standardise use of the MALT. ${ }^{10}$ Mean corpuscular volume (MCV) and gamma-glutamyl-transpeptidase $(\gamma$-GT) were considered altered when $\geqslant 98.0 \mathrm{fl}$ and $\geqslant 45 \mathrm{U} / \mathrm{l}$.

\section{Conduct of the study}

Cases and controls were interviewed by a neurologist who was blind to the classification of cases. Interviews were done within 48 hours of the seizure (cases) or admission (controls), after informed consent. When the interview was impossible (patient unable to cooperate), the next-of-kin was interviewed (proxy respondent). Proxy respondents were necessary for 67 cases $(23 \%)$ and 75 controls $(17 \%)(p<0.05)$. When neither the case nor the proxy was available or able to respond, the case was considered lost. When neither the control nor a proxy was available, the control was replaced.

MCV was not recorded for $14 \%$ and $\gamma$-GT for $19 \%$ of subjects. A CT scan was done in all cases and an EEG in all but 19. Other examinations (for example, magnetic resonance imaging) were scheduled according to the clinical decisions in each centre, but the results were not used to classify patients.

\section{Statistical analysis}

The role of the risk factors was estimated by calculating the odds ratios (OR), with 95\% confidence intervals (CI) determined according to Cornfield. ${ }^{12}$ The $\chi^{2}$ test and Student's two tailed $t$ test were used where appropriate. The percentage of non-responses was less than $2 \%$ for quantification of alcohol use, less than $5 \%$ for demographic data, and less than $10 \%$ for the MALT, problems related to alcoholism, and drinking patterns. The percentages of missing data were similar for cases and controls, except that MCV and $\gamma$-GT were missing more frequently among controls, and problems with alcoholism were missing more frequently among cases.

Assuming a prevalence of exposure of $5 \%$, the sample needed to detect a risk of 2.5 with an alpha error of 0.05 and a beta error of 0.20 was 215 cases with two controls per case, and 301 cases with one control per case. ${ }^{12}$ 
Table 2 Grams of alcohol per day for each beverage used by current drinkers (cases and controls)

\begin{tabular}{|c|c|c|c|c|}
\hline \multirow[b]{2}{*}{ Beverage* } & \multicolumn{2}{|l|}{ Men } & \multicolumn{2}{|l|}{ Women } \\
\hline & Cases & Controls & Cases & Controls \\
\hline White wine & 13.4 (17.4) & $13.7(20.1)$ & $6.0(6.3)$ & 7.2 (10.3) \\
\hline Red wine & $28.1(25.3)$ & 24.5 (21.5) & $17.7(13.2)$ & 14.1 (10.3) \\
\hline Beer & $7.2(16.8)$ & 3.5 (12.7) & $2.9(7.1)$ & $5.8(9.8)$ \\
\hline Aperitifs $\dagger$ & $1.6(2.0)$ & $4.6(9.6)$ & $0.9(0.3)$ & $4.1(6.7)$ \\
\hline "Bitters" $\ddagger$ & $3.2(4.4)$ & $4.2(6.9)$ & $1.4(0.5)$ & $3.6(7.0)$ \\
\hline Spirits§ & $10.1(30.0)$ & $6.6(12.9)$ & $4.4(5.2)$ & $1.4(0.0)$ \\
\hline "Laced" coffeef & $1.2(1.4)$ & $1.0(1.0)$ & $0.9(0.8)$ & $0.9(1.7)$ \\
\hline
\end{tabular}

${ }^{*}$ Mean (SD); all comparisons NS.

†Including vermouths and fortified wines (for example, port, sherry, marsala).

fliqueurs are included here, such as those commonly drunk at the end of a meal ("digestifs").

§Including "grappa", whisky, gin, vodka, rum, cognac, and other distillates.

IA local beverage made of coffee, with "grappa" or brandy added.

\begin{tabular}{|c|c|c|c|}
\hline & $\begin{array}{l}\text { Cases (\%) } \\
\text { No. }(n=181)\end{array}$ & $\begin{array}{l}\text { Controls }(\%) \\
\text { No. }(n=253)\end{array}$ & $\mathrm{p}$ \\
\hline Drinking 1 beverage & $62(34)$ & $68(27)$ & NS \\
\hline Drinking $\geqslant 4$ beverages & $51(28)$ & $70(28)$ & NS \\
\hline Between meals drinkers & $36(20)$ & $46(18)$ & NS \\
\hline Binge drinkers & $24(13)$ & $39(15)$ & NS \\
\hline Wine (red or white) & 175 (97) & $247(98)$ & NS \\
\hline$\geqslant 3$ days $/$ week & $153(87)$ & 220 (89) & NS \\
\hline$\geqslant 3$ occasions/day & $15(9)$ & $17(7)$ & NS \\
\hline$\geqslant 3$ glasses/occasion & 20 (11) & 27 (11) & NS \\
\hline Beer & $70(39)$ & $89(35)$ & NS \\
\hline$\geqslant 3$ days/week & $24(34)$ & $20(23)$ & NS \\
\hline$\geqslant 2$ occasions/day & $11(16)$ & $14(16)$ & NS \\
\hline$\geqslant 2$ cans/occasion & $10(14)$ & $8(9)$ & NS \\
\hline High strength beverages & $96(53)$ & $136(54)$ & NS \\
\hline$\geqslant 3$ days/week & $35(36)$ & $38(28)$ & NS \\
\hline$\geqslant 2$ occasions/day & $6(6)$ & $14(10)$ & NS \\
\hline$\geqslant 2$ glasses/occasion & $2(2)$ & $5(4)$ & NS \\
\hline
\end{tabular}

\section{RESULTS}

We included 324 patients, 303 with a first ever seizure and 21 with a first medically evaluated seizure. The two groups were similar with respect to the main demographic characteristics. Thirty one cases $(10 \%)$ were excluded: four were discharged or transferred to other hospitals before interview, three refused, seven died before the interview, and 17 had no surrogate responders. Thus we ended up with 293 cases ( 160 men, 133 women). There was no significant difference between included and excluded cases in age, sex, schooling, marital status, occupation, place of birth, MCV, $\gamma$-GT, medical part of the MALT, time and type of underlying aetiology, and type of seizure. In the cases, partial seizures with or without secondary generalisation were the predominant pattern (151 patients, $52 \%$ ) followed by generalised tonic-clonic seizures $(95,32 \%)$ and by complex partial seizures with/without secondary generalisation $(47,16 \%)$. The leading cause of seizures was stroke $(161,55 \%)$, followed by brain tumour $(109,37 \%)$ and head trauma $(23,8 \%)$. We collected 444 of the 586 expected controls $(76 \%)$, giving a ratio of 1.5 controls per case, 1.2-1.9 in each aetiological category (table 1 ).

Cases and controls were similar with respect to mean age, schooling, marital status, residency, place of birth, road accidents, problems with the law, and dismissals from work. Cases were more frequently employed $(42 \%$ v 34\%, p < 0.05 ) than controls.

The risk of first seizure in alcoholics (MALT >10) was not significantly higher than for non-alcoholics, for men (OR 1.2, $95 \%$ CI 0.4 to 3.2 ) or women $(1.5,0.1$ to 54.1$)$. It was also not higher for men $(1.2,0.5$ to 2.8$)$ and women (1.5, 0.2 to 9.2) with borderline values (MALT 6-10). Altered biological markers of alcoholism were similarly distributed in cases and controls (men: MCV 10\% v 8\%, $\gamma$-GT 29\% v 25\%; women: MCV 3\% $v 2 \%, \gamma$-GT $21 v 14 \%$; NS).

Current drinkers did not have a higher risk of first seizure than non-drinkers for men (OR $1.0,95 \%$ CI 0.5 to 1.9 ) or women (1.4, 0.8 to 2.3). The mean age at starting for current drinkers was similar in cases and controls, both for men (17.7 $v 19.0$ years, NS) and women (20.0 v 19.0 years, NS). Ex-drinkers had a risk of first seizure lower than 1 for both sexes (men 0.7, 0.3 to 2.0; women $0.7,0.3$ to 2.1 ).

The mean ADAA was similar for current drinker cases and controls of both sexes: men $39.5 v 37.2 \mathrm{~g} /$ day; women $19.2 v$ $18.5 \mathrm{~g} /$ day; NS). The average amount of each beverage drunk (table 2) was similar for seizure patients and controls, for both sexes. No difference was found in drinking patterns between cases and controls for men and women separately (data not shown) and for both sexes combined (table 3). As the risk was no higher for occasional drinkers than non-drinkers, we pooled the two categories for further analysis. The risk was not significant in all categories of alcohol consumption (table 4).

Considering the timing of seizures (all aetiologies combined), the mean ADAA for current drinkers was no different for cases and controls, either acute $(34.2 v 32.1 \mathrm{~g} / \mathrm{day}, \mathrm{NS})$ or remote $(27.6 v 30.7 \mathrm{~g} /$ day, NS $)$. After combining patients with acute and remote symptomatic seizures, the mean ADAA was significantly higher for cases with head trauma (52.1 $v 25.8$ g/day, p < 0.05), slightly higher for stroke $(34.2 v 30.5$, NS), and lower for brain tumour (26.1 $v 36.2$, NS). Tables 5 and 6 show the risk of first seizures in relation to seizure timing and aetiology.

Table 4 Average daily intake of absolute alcohol (ADAA) in cases and controls during the six months before seizure (cases) or admission (controls) *

\begin{tabular}{|c|c|c|c|c|c|c|}
\hline \multirow[b]{2}{*}{ ADAA (g/day) } & \multicolumn{2}{|l|}{ Men } & \multicolumn{2}{|l|}{ Women } & \multicolumn{2}{|l|}{ Both sexes } \\
\hline & $\begin{array}{l}\text { Cases/ } \\
\text { controls }\end{array}$ & OR $(95 \% \mathrm{CI})$ & $\begin{array}{l}\text { Cases/ } \\
\text { controls }\end{array}$ & OR $(95 \% \mathrm{Cl})$ & $\begin{array}{l}\text { Cases/ } \\
\text { controls }\end{array}$ & OR $(95 \% \mathrm{Cl})$ \\
\hline$>100$ & $10 / 11$ & $1.6(0.5$ to 4.7$)$ & $0 / 1$ & - & $10 / 12$ & $1.4(0.5$ to 3.5$)$ \\
\hline $51-100$ & $23 / 26$ & $1.5(0.7$ to 3.4$)$ & $2 / 0$ & - & $25 / 26$ & 1.6 (0.8 to 3.0 ) \\
\hline $26-50$ & $25 / 48$ & $0.9(0.4$ to 1.9$)$ & $6 / 9$ & $1.1 \quad(0.3$ to 3.4$)$ & $31 / 57$ & 0.9 (0.5 to 1.5$)$ \\
\hline $1-25$ & $62 / 94$ & $1.2(0.6$ to 2.1$)$ & $53 / 64$ & $1.3(0.8$ to 2.2$)$ & $115 / 158$ & $1.2(0.8$ to 1.7$)$ \\
\hline Reference category $\dagger$ & $27 / 47$ & 1 & $65 / 103$ & 1 & $92 / 150$ & 1 \\
\hline
\end{tabular}

*Ex-drinkers (20 cases and 41 controls) are not included.

†Reference category includes non-drinkers and occasional drinkers. 
Table 5 Average daily intake of absolute alcohol (ADAA) in cases and controls during the six months before seizure (cases) or admission (controls) ${ }^{*}$, stratified by timing of seizure

\begin{tabular}{|c|c|c|c|c|}
\hline \multirow[b]{2}{*}{ ADAA (g/day) } & \multicolumn{2}{|c|}{ Acute symptomatic } & \multicolumn{2}{|c|}{ Remote symptomatic } \\
\hline & $\begin{array}{l}\text { Cases/ } \\
\text { controls }\end{array}$ & OR $(95 \% \mathrm{Cl})$ & $\begin{array}{l}\text { Cases/ } \\
\text { controls }\end{array}$ & OR $(95 \% \mathrm{Cl})$ \\
\hline$>100$ & $9 / 10$ & $1.6(0.5$ to 4.4$)$ & $1 / 2$ & $0.7(0.1$ to 10.8$)$ \\
\hline $51-100$ & $21 / 17$ & 2.1 (1.0 to 4.6$)$ & $4 / 9$ & $0.6(0.2$ to 2.6$)$ \\
\hline $1-50$ & $110 / 164$ & $1.2(0.8$ to 1.7$)$ & $36 / 51$ & $1.0(0.5$ to 2.0$)$ \\
\hline Reference category $\dagger$ & $64 / 110$ & 1 & $28 / 40$ & 1 \\
\hline
\end{tabular}

*Ex-drinkers are not included.

†Reference category includes non-drinkers and occasional drinkers.

Table 6 Average daily intake of absolute alcohol (ADAA) in cases and controls during the six months before seizure (cases) or admission (controls) *, stratified by underlying pathology

\begin{tabular}{|c|c|c|c|c|c|c|}
\hline \multirow[b]{2}{*}{ ADAA (g/day) } & \multicolumn{2}{|l|}{ Stroke } & \multicolumn{2}{|c|}{ Head trauma } & \multicolumn{2}{|c|}{ Brain tumour } \\
\hline & $\begin{array}{l}\text { Cases/ } \\
\text { controls }\end{array}$ & OR $(95 \% \mathrm{Cl})$ & $\begin{array}{l}\text { Cases/ } \\
\text { controls }\end{array}$ & OR $(95 \% \mathrm{Cl})$ & $\begin{array}{l}\text { Cases/ } \\
\text { controls }\end{array}$ & OR $(95 \% \mathrm{Cl})$ \\
\hline$>100$ & $6 / 5$ & $2.5(0.6$ to 10.0$)$ & $3 / 1$ & $3.4(0.2$ to 109.2$)$ & $1 / 6$ & $0.2(0.1$ to 1.8$)$ \\
\hline $51-100$ & $14 / 19$ & $1.5(0.7$ to 3.5$)$ & $2 / 3$ & $0.8(0.1$ to 8.6$)$ & $9 / 4$ & 2.7 (0.7 to 11.5$)$ \\
\hline $1-50$ & $81 / 134$ & 1.3 (0.8 to 2.0$)$ & $10 / 18$ & $0.6(0.1$ to 2.7$)$ & $55 / 63$ & $1.1 \quad(0.6$ to 1.9$)$ \\
\hline Reference category $\dagger$ & $46 / 95$ & 1 & $7 / 8$ & 1 & $39 / 47$ & 1 \\
\hline
\end{tabular}

*Ex-drinkers are not included.

†Reference category includes non-drinkers and occasional drinkers.

\section{DISCUSSION}

Seizures are defined as symptomatic when they are considered the consequence of a known or suspected cerebral dysfunction such as head injury, cerebrovascular accident, brain tumour, and others. ${ }^{1}$ However, the identification of an epileptogenic lesion in a patient's history does not exclude the role of other factors. For example, why do some patients with vascular lesions in similar brain areas develop seizures while others do not? Does the factor considered as "aetiological" explain the risk of having a seizure, or are other factors needed? From an epidemiological point of view each risk factor should be evaluated as one of several that dictates the higher or lower probability of a first seizure.

Alcohol use is a powerful risk factor for a first seizure for adults of both sexes; its strength is high for idiopathic/ cryptogenic seizures with a dose-response effect, while its role in symptomatic seizures is more controversial. Acute symptomatic seizures were only slightly related to alcohol in our previous study, ${ }^{5}$ while the New York study ${ }^{4}$ showed a two- to tenfold risk for alcohol users (although significant only above 200 $\mathrm{g}$ /day). Furthermore, in our previous study we did not find any relation between alcohol and remote symptomatic seizures. ${ }^{5}$ Clinical series have reported a high frequency of symptomatic ${ }^{13}$ or partial $^{14}$ seizures in alcoholics. These differences may depend on various factors, including different populations, ascertainment methods, levels of exposure, and drinking habits. Confounding could also play a role: as heavy alcohol use is a risk factor for stroke ${ }^{6}$ and head trauma, any change in risk could be erroneously attributed to alcohol. To control for confounding we matched our cases to controls having the same underlying pathology, to eliminate its effect on the risk of seizures. Since stroke, head trauma, and brain tumour account for the majority of symptomatic seizures in population studies, ${ }^{23}$ we limited our sample to these three categories.

The main finding is that alcohol use did not increase the risk of a first symptomatic seizure in both sexes. Current drinkers were similarly represented among patients with seizures and non-epileptic controls, and the mean quantity of alcohol consumed, in total and for each beverage, was similar for cases and controls of both sexes. The risk did not increase significantly, even with ADAA higher than 100 g/day. No doseresponse pattern was detected. $\mathrm{Ng}$ and colleagues ${ }^{4}$ found a high risk for those drinking more than $200 \mathrm{~g} /$ day, but we had only one person (a control) who drank this much. Thus, we cannot rule out that there may be an association for very heavy alcohol consumption, as our sample was not large enough to draw conclusions for such high levels.

The mean ages for starting drinking and drinking patterns were similar for cases and controls; biological markers and the alcoholism test were also similarly distributed. All these observations point in the same direction and seem to exclude any association between alcohol use and a first symptomatic seizure. One possible explanation of the difference between this and other studies is that the associations observed were a result of confounding.

No substantial difference was evident between acute and remote symptomatic seizures, although acute seizures had a slightly higher risk in all alcohol consumption categories. Considering each putative cause, we found a minimal (not statistically significant) effect of alcohol for stroke and head trauma patients, but only for high doses in the latter.

Some possible flaws of our study need to be discussed. The identification of alcoholics and the measures of alcohol intake were based on a questionnaire and self reporting; this could lead to under-reporting of an undesirable social behaviour, such as heavy alcohol use. However, self reporting is traditionally considered superior to biochemical markers, ${ }^{15}$ and questionnaires have greater sensitivity and positive predictive value than blood chemistry tests in the identification of alcoholics; in addition, there is no reason to think of a different recall between cases and controls. On the other hand, alcohol exposure could have been overestimated in hospital controls, though this seems improbable as the ADAA in controls was similar to that in our other study with different controls, ${ }^{4}$ and in a survey on the general population in the same study area. ${ }^{16}$

Some problems arise from the larger proportion of proxies interviewed among cases than controls, and the incompleteness of control recruitment. In a previous reliability analysis, ${ }^{10}$ 
proxies gave a slightly higher ADAA, which was not statistically significant; for this reason a bias caused by the larger number of proxies would have increased the ADAA of cases, with consequent higher risk estimates. We were able to recruit less than two controls per case, because of the difficulty of matching for the underlying pathology. If the control:case ratio were higher for the aetiology thought to be less frequently associated with alcohol use (brain tumour), this could have lowered the risk estimates; however, this was not the case as brain tumours had the lowest ratio (134:109, that is 1.2). Finally, compared to incidence studies, ${ }^{2}{ }^{3}$ we had a lower percentage of head trauma and a higher percentage of brain tumour, given the type of participating centres (mostly neurology departments).

In conclusion, this study provides no evidence of any association between alcohol use and a first symptomatic seizure, either acute or remote, and gives some clues to explain better the relation between alcohol and seizures. When another powerful aetiological factor, such as stroke, brain tumour, or head trauma is identified, alcohol use no longer has any influence. Furthermore, if alcohol causes a generic lowering of the seizure threshold, its effect should be similar in idiopathic and symptomatic seizures, which is not the case. In fact the effect of alcohol seems specific only for idiopathic/ cryptogenic seizures, although its mechanism is not yet understood.

\section{ACKNOWLEDGEMENTS}

We thank Prof. Matti Hillbom for valuable advice, Ms Judy Baggott for editorial revision, and Mrs Susanna Franceschi for typing the manuscript. This work was supported in part by a grant from Regione Lombardia.

Members of the ARES Group: Luigi Sironi, MD, Lorenzo Carenini, MD, Giovanni Corso, MD, U.O. di Neurologia, Ospedale Regionale, Aosta; Francesco Brignolio, MD, Enrica Duc, MD, M Gabriella Saracco, MD, Divisione di Neurologia, Ospedale Civile, Asti; Vincenzo Nardozza, MD, Umberto Masazza, MD, Maurizio Gionco, MD, Divisione di Neurologia, Ospedale degli Infermi, Biella; Enzo Grasso, MD, Piero Meineri, MD, M Gabriella Rosso, MD, Divisione di Neurologia, Ospedale Santa Croce, Cuneo; Franco Grassi, MD, Divisione di Neurologia, Ospedale "G Salvini", Garbagnate Milanese; Cesare Morandi, MD, Monica Tottola, MD, Divisione di Neurologia, Ospedale C Poma, Mantova; Andrea Landi, MD, Divisione di Neurochirurgia, Ospedale "S Gerardo", Monza; Paola Naldi, MD, Emanuela Terrazzi, Clinica Neurologica, Università "A Avogadro", Novara; Carlo Buffa, MD, Enrico Rocci, MD, Divisione di Neurologia, Ospedale di Novi Ligure; Romualdo Badino, MD, Divisione di Neurologia, Ospedale "S Corona", Pietra Ligure; Maria Favero, MD, Divisione di Neurologia, Ospedale E Agnelli, Pinerolo; Rossana Cremo, MD, Enrico Morgando, MD, DEA di Neurologia, Ospedale Molinette, Torino; Renato Bacci, MD, Carmelo Labate, MD, Divisione di Neurologia, Ospedale Mauriziano, Torino; Gigliola Chianale, MD, Daniela Cassano, MD, Divisione di Neurologia, Ospedale G Bosco, Torino; Paolo Provera, MD, Carlo Brite, MD, Divisione di Neurologia, Ospedale Civile, Tortona; Francesco Paladin, MD, Divisione Neurologica, Ospedale Civile, Venezia.

\section{Authors' affiliations}

M Leone, F Monaco, Clinica Neurologica, Università A. Avogadro, Novara

C Tonini, Divisione di Neurologia, Ospedale G. Salvini, Garbagnate Milanese

G Bogliun, E Beghi, Clinica Neurologica, Ospedale S. Gerardo,

Monza

R Mutani, Clinica Neurologica II, Università di Torino

E Bottacchi, U.O. di Neurologia e Neurofisiopatologia, Ospedale Regionale, Aosta

P Gambaro, Divisione di Neurologia, Ospedale Sacco, Milano

E Rocci, Divisione di Neurologia, Ospedale di Novi Ligure

T Tassinari, Divisione di Neurologia, Ospedale S. Corona, Pietra Ligure

C Cavestro, Laboratorio di Farmacologia Clinica, Istituto di Ricerche

Farmacologiche Mario Negri, Milano

Competing interests: none declared

\section{REFERENCES}

1 Commission on Epidemiology and Prognosis, International League against Epilepsy. Guidelines for epidemiologic studies on epilepsy. Epilepsia 1993:34:592-6.

2 Hauser WA, Annegers JF, Kurland LT. Incidence of epilepsy and unprovoked seizures in Rochester, Minnesota: 1935-1984. Epilepsia 1993;34:453-68.

3 Jallon P, Goumaz M, Haenggeli C, et al. Incidence of first epileptic seizures in the canton of Geneva, Switzerland. Epilepsia 1997;38:547-52

$4 \mathrm{Ng}$ SKC, Hauser WA, Brust JCM, et al. Alcohol consumption and withdrawal in new-onset seizures. N Engl J Med 1988;319:666-73.

5 Leone $M$, Bottacchi $E$, Beghi $E$, et al. Alcohol use is a risk factor for a first generalized tonic-clonic seizure. Neurology 1997;48:614-20.

6 Beghi E, Bogliun G, Cosso P, et al. Stroke and alcohol intake in a hospital population. A case-control study. Stroke 1995;26:1691-6.

7 Jennett B. Epidemiology of head injury. J Neurol Neurosurg Psychiatry 1996;60:362-9.

8 Commission on Classification and Terminology of the International League Against Epilepsy. Proposal for revised clinical and electroencephalographic classification of epileptic seizures. Epilepsia 1981;22:489-501.

9 Herman B, Schulte BPM, Van Luijk JH, et al. Epidemiology of stroke in Tilberg, the Netherlands: the population-based stroke incidence register, introduction and preliminary result. Stroke 1980;11:162-5.

10 The ALCE Study Group. A case-control study on alcohol and seizures: rationale study design; protocol and data collection. Ital J Neurol Sci 1997; 18:119-24

11 Feuerlein W, Ringer C, Kufner H, et al. Diagnose des Alkoholismus. Der Münchner Alkoholismustest (MALT). Munch Med Wschr 1977; 1 19:1275-86.

12 Schlesselman JJ. Case-control studies. Design, conduct, analysis. New York: Oxford University Press, 1982.

13 Hillbom ME. Occurrence of cerebral seizures provoked by alcohol abuse. Epilepsia 1980;21:459-66.

14 Brathen G, Brodtkorb E, Helde G, et al. The diversity of seizures related to alcohol use. A study of consecutive patients. Eur J Neurol 1999;6:697-703

15 Bernadt MW, Mumford J, Taylor C, et al. Comparison of questionnaire and laboratory tests in the detection of excessive drinking and alcoholism. Lancet 1982;1:325-8.

16 GESIA. Società Italiana di Alcologia. Consumi, prevalenze e mortalitò nelle Regioni Italiane, 1985-94. www.dfc.unifi. it/SIA 